\title{
Low concentration of xylitol improves children tooth protection against Streptococcus mutans biofilm formation
}

\author{
Dorota Kościelniak $^{1}$, Iwona Gregorczyk-Maga ${ }^{1}$, Anna Jurczak ${ }^{1}$, Małgorzata Staszczyk ${ }^{1}$, Iwona Kołodziej ${ }^{1}$, Marcin Magacz ${ }^{2}$, Karolina \\ Kędziora $^{2}$, Monika Papież ${ }^{3}$, Palina Vyhouskaya ${ }^{2}$, Małgorzata Jamka-Kasprzyk ${ }^{1}$ and Wirginia Krzyściak ${ }^{2 *}$ \\ ${ }^{1}$ Department of Pediatric Dentistry, Institute of Dentistry, Jagiellonian University Medical College, Montelupich 4, 31-155 Krakow, Poland \\ ${ }^{2}$ Department of Medical Diagnostics, Faculty of Pharmacy, Jagiellonian University Medical College, Medyczna 9, 30-688 Krakow, Poland \\ ${ }^{3}$ Department of Cytobiology, Faculty of Pharmacy, Jagiellonian University Medical College, Medyczna 9, 30-688 Krakow, Poland
}

\begin{abstract}
Objective: Dental caries is the most prevalent chronic disease in childhood. It is a social disease, which causes search for effective methods of its prevention. Due to its inhibitory action on Streptococcus mutans, xylitol is a readily used supplement. The purpose of the study was a determination of the effect of $0.01 \%$ concentration of xylitol on monospecies $S$. mutans biofilm formation.

Design: Clinical strains were acquired from 64 children aged $4.7 \pm 0.81$ years. The study group included children with caries and patients without carious lesions. The isolates identified using a MALDI-TOF mass spectrometer. The effect of $0.01 \%$ xylitol on monospecies biofilm formation after 8, 24, 48 and $72 \mathrm{~h}$ of culturing was evaluated. The produced biofilms were evaluated by determining the biofilm biomass, microorganism concentration and analyzing structure in a scanning electron microscope.
\end{abstract}

Results: The biofilm biomass treated with xylitol was, at every time point, significantly lower $(\mathrm{p}<0.001)$, in both study groups of children compared to the biofilm not treated with xylitol. A statistically significant decrease in the biofilm-forming capacity with xylitol in CFU/mL was obtained after $48 \mathrm{~h}$ in both groups.

Conclusions: The anti-biofilm efficacy of xylitol at low concentrations, justifies its use in caries prevention in children.

\section{Introduction}

According to World Health Organization dental caries is a local pathological process of extracorporeal origin, leading to the decalcification of the enamel, the breakdown of hard tooth tissues and, consequently, cavities' formation. Caries is a chronic infectious disease that occurs when demineralization processes are predominant over remineralization. For this to happen co-occurrence of 4 factors is necessary: the proper composition of dental plaque-the presence of cariogenic bacteria that form biofilms, in particular S. mutans, high carbohydrate intake (especially simple sugars), which as a result of mainly cariogenic microorganisms' metabolism are transformed into organic acids, susceptibility of the host's tooth tissues to these acids, and disturbances in the functioning of salivary defense mechanisms and time [1-3].

Caries growth can currently be observed, and this is largely related to an increase in the content of simple sugars in the diet. At the beginning of the 21st century, caries became the most prevalent chronic disease in children [3]. A special type of caries is early childhood caries (ECC) affecting children under 6 years of age. The reason for the cariogenic bacteria presence in the oral cavity is the phenomenon of transmission from mother to child (vertical transmission) [4]. Due to the scale of the problem, preventive measures have been introduced for the widest application, among which fluoride prophylaxis is the most commonly used and supported by evidence for its anti-caries effectiveness [5].

Such prophylaxis is based on regular use by patients of fluoride dentifrices used in exogenous prophylaxis (toothpastes, rinses, gels, foams, varnishes) as well as in endogenous prevention (e.g., fluoridation of drinking water, milk, salt) [6,7]. The increase in the tooth enamel fluorosis cases number observed in recent decades and the reluctance of some social groups to use fluoride compounds brings the need for other non-fluoride-based caries methods of prevention, especially in the youngest age groups.

Researchers are focusing their efforts on the search for and development of methods for non-fluoride prevention of dental caries, which would complement fluoride activity in the remineralization and inhibit demineralization. These technologies are used in toothpastes and other dentifrices with nanohydroxyapatites, arginine, lactoperoxidase system and with xylitol [2,8-10].

Xylitol is a five-carbon polyol naturally occurring in many plants, e.g., in birch bark, from which it is obtained for food purposes [2]. Like sucrose, it has a sweet taste, but unlike it, it is not metabolized by microorganisms to organic acid [11]. This fact enables its use as a non-cariogenic sugar substitute. In addition, its ability to increase salivary flow promotes the remineralization processes, increasing its

${ }^{*}$ Correspondence to: Wirginia Krzyściak $\mathrm{PhD}$, Department of Medical Diagnostics, Faculty of Pharmacy, Jagiellonian University Medical College, Medyczna 9, 30-688 Krakow, Poland, Tel: +4812 6205760, fax: +4812 6205400, E-mail: wirginiakrzysciak@cm-uj.krakow.pl

Key words: biofilm, childhood caries, S. mutans, xylitol

Received: January 21, 2019; Accepted: February 04, 2019; Published: February 08, 2019 
buffer capacity and reducing the amount of cariogenic microorganisms in the dental plaque by impairing their adhesion processes $[2,11]$. In the presence of xylitol as the only source of carbohydrates, $S$. mutans is unable to grow [2]. Xylitol taken up by a bacterial cell undergoes phosphorylation in its interior to xylitol 5-phosphate as a result of the phosphoenolpyruvate-dependent phosphotransferase system (PTS). This product accumulates in the cell causing its vacuolization. To reduce its content, xylitol 5-phosphate is removed from the cell after prior dephosphorylation (Figure 1). Such a futile cycle deprives the cell of energy gain, which contributes to its growth inhibition. Nevertheless, the long-term exposure of $S$. mutans to xylitol leads to the selection of strains resistant to pentitol, which are characterized by low PTS activity [2].

Currently, xylitol has been approved by several dozen countries as a treatment to be used in caries prevention. It is used in forms of lozenges, chewing gums, sweeteners, syrups, toothpastes and rinses [11].

In this study, we present the low concentration of xylitol influence on the ability of biofilm formation exhibited by clinical strains of $S$. mutans derived from children suffering from dental caries and children without carious lesions.

\section{Materials and methods}

\section{Study groups}

The study protocol was approved by the Bioethics Committee of the Jagiellonian University on the basis of meeting the requirements of the Helsinki Declaration (2008) after acceptance of the prepared study plan (no 1072.6120.183.2017 of 26.10.2017).

The study was carried out from November 2017 to May 2018 and included 64 patients of the University Clinic of Pediatric Dentistry. Criteria for inclusion in the study were clinically diagnosed dental caries in children aged 2-6 years. Exclusion criteria were: age less than 2 years, age over 6 years, diabetes, the use of certain drugs during the previous

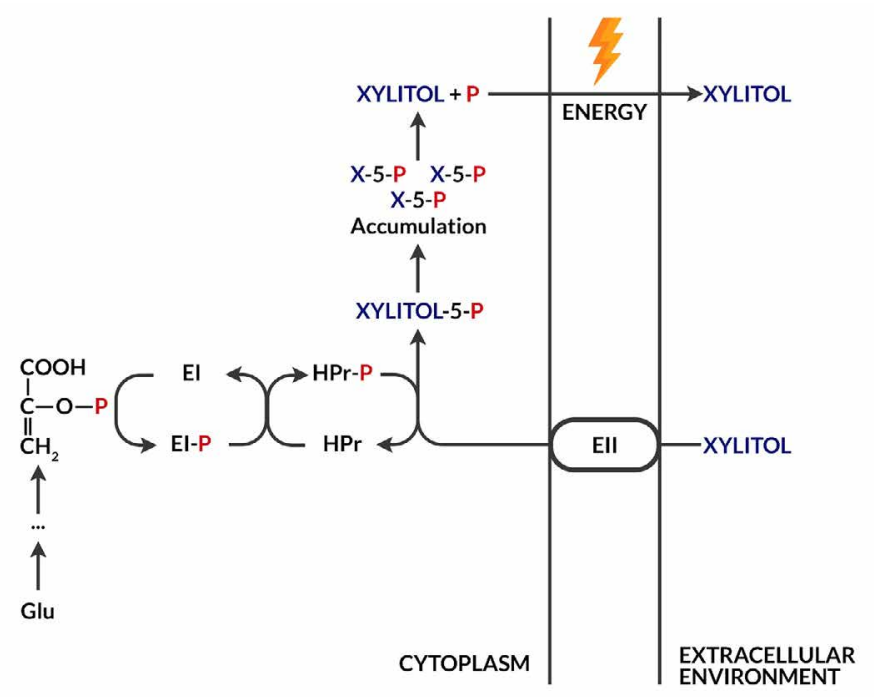

Figure 1. Futile xylitol cycle. The phosphoenolpyruvate-derived (PEP) phosphate group, which is an intermediate product of glycolysis, is transferred by cytoplasmic EI and HPr enzymes to a phosphoenolpyruvate-dependent phosphotransferase (PTS) system, which then allows xylitol transport inside the cell with simultaneous phosphorylation. The product, xylitol 5-phosphate, cannot be used as a source of energy and accumulates, leading to the vacuolization of the bacterial cell. Excess xylitol-5-phosphate after prior dephosphorylation can be removed from the cell, but the process requires energy
3 months (i.e., antibiotics, non-steroidal anti-inflammatory drugs, corticosteroids, vitamins), periodontitis, other inflammatory changes of the oral mucosa such as candidiasis, as well as the participant's legal guardian's withdrawal from participation in the study. Bacterial strains were isolated from plaque samples from qualified participants of the study. The study group included children with advanced ECC (33 children, average age: $4.7 \pm 0.73$ years) and without carious lesions (31 children, average age: $4.71 \pm 0.9$ years).

The condition of children's teeth was determined using the International Caries Detection and Assessment System (ICDAS). Children with carious lesions were classified in the study group, which corresponded to codes 3-6 according to the ICDAS classification [1214]. The control group included children with teeth not affected by carious lesions (code 0 according to ICDAS) and with early carious lesions limited to enamel in the form of its opacity, which corresponds to ICDAS 1 and 2 codes.

The presence and amounts of dental plaque were evaluated on the basis of a simplified oral hygiene index (OHI-S index) [15].

\section{Obtaining dental plaque from study participants}

Plaque was extracted from all tooth surfaces via a half-minute brushing with a sterile brush mounted on a sterile contra-angle handpiece from the dental unit. In cases of children with dentophobia symptoms, the doctor removed the plaque manually using a brush placed in the low-speed tip disconnected from the unit. The legal guardians of the study participants were instructed on how to prepare children for the examination, and the details of the study as outlined by the research team were passed to them before giving their consent. Plaque samples were collected in the morning between 9 and 10, on an empty stomach, preceded by rinsing mouth with deionized water and after evaluation of the presence and amount of plaque (OHI-S). Test tubes with dental plaque were sonicated in an ultrasonic homogenizer (Hielscher UP50H) (30 s, 25\% amplitude). Subsequently, the obtained material was mixed to obtain a homogeneous suspension and incubated under microaerophilic conditions $\left(10 \% \mathrm{CO}_{2}\right)$. The cells were collected in the logarithmic phase of growth and were washed thrice with 40 $\mathrm{mM}$ potassium phosphate buffer ( $\mathrm{pH}$ 7.0). A homogeneous bacterial suspension in a volume of $50 \mu \mathrm{L}$ was used in a conventional culturing method, using a selective medium, in three 10-fold dilutions for each developed sample, as described in our earlier study [16]. The obtained material was incubated under $85 \% \mathrm{~N}_{2}, 10 \% \mathrm{CO}_{2}, 5 \% \mathrm{O}_{2}$ conditions at $37^{\circ} \mathrm{C}$ for $24-48 \mathrm{~h}$. The cut-off point for the positive samples was the number of bacterial colonies $>10,000$ cells $/ \mathrm{mL}$ (Figure 2 ). Phenotypic identification was based on the morphological characteristics of bacterial colonies cultured on blood agar and the type of hemolysis. Dental plaque dilutions were made sequentially and inoculated on HLR-S (HL Ritz) medium. After culturing, the colonies were numbered by $\mathrm{CFU} / \mathrm{mL}$ (colony forming units $/ \mathrm{mL}$ ).

\section{Description of isolated $S$. mutans species}

Pure isolates of S. mutans were inoculated from the HLR-S selective medium to blood agar (TSA) supplemented with $5 \%$ sheep blood while being grown under the standard conditions specified Krzyściak, et al. [16]. Colonies' morphologies, hemolysis factors and sensitivities to drugs that exhibited specific heterogeneity within the same bacterial species were assessed. Gram staining was performed for initial differential diagnosis, allowing the distinction between Gram-positive and Gram-negative bacteria species. 


\section{Identification}

Isolated $S$. mutans species were identified by mass spectrometry assisted with desorption/laser ionization mass with a time-of-flight analyzer(MALDI-TOF MS). The ribosomal protein profile was evaluated using a Bruker MALDI Biotyper 1.0 analyzer. SCORE $\geq 2.0$ results were considered to be $S$. mutans, while $<2.0$ scores were considered to be other than $S$. mutans and were not taken into consideration. These results were compared with the updated, commercially available Bruker database (Figure 3).

\section{Preparation of homogeneous $S$. mutans mixtures}

Only a homogeneous suspension of clinical strains of $S$. mutans was used in the study. Individual $S$. mutans colonies were cultured under microaerophilic conditions $\left(6 \mathrm{~h}, 37^{\circ} \mathrm{C}, 10 \% \mathrm{CO}_{2}\right)$ in $5 \mathrm{~mL}$ BHI broth (Broth heart infusion, Merck, Darmstadt, Germany), at a final concentration of $0.01 \%$ xylitol (origin: Finnish birch). S. mutans strains were collected during logarithmic phase growth, and washed twice with PBS buffer (phosphate-buffered saline, $40 \mathrm{mM}, \mathrm{pH}$ 7.0). The microbial growth process was determined every 5 minutes by means of flow cytometry (LSRII, BD Immunoassay Systems, San Jose, CA, USA). Cell aggregates and conglomerates were discarded using wide-spread (FSC) and lateral light scatter (SSC) gating. Cells from the logarithmic growth phase were used for the study after overnight standardization of

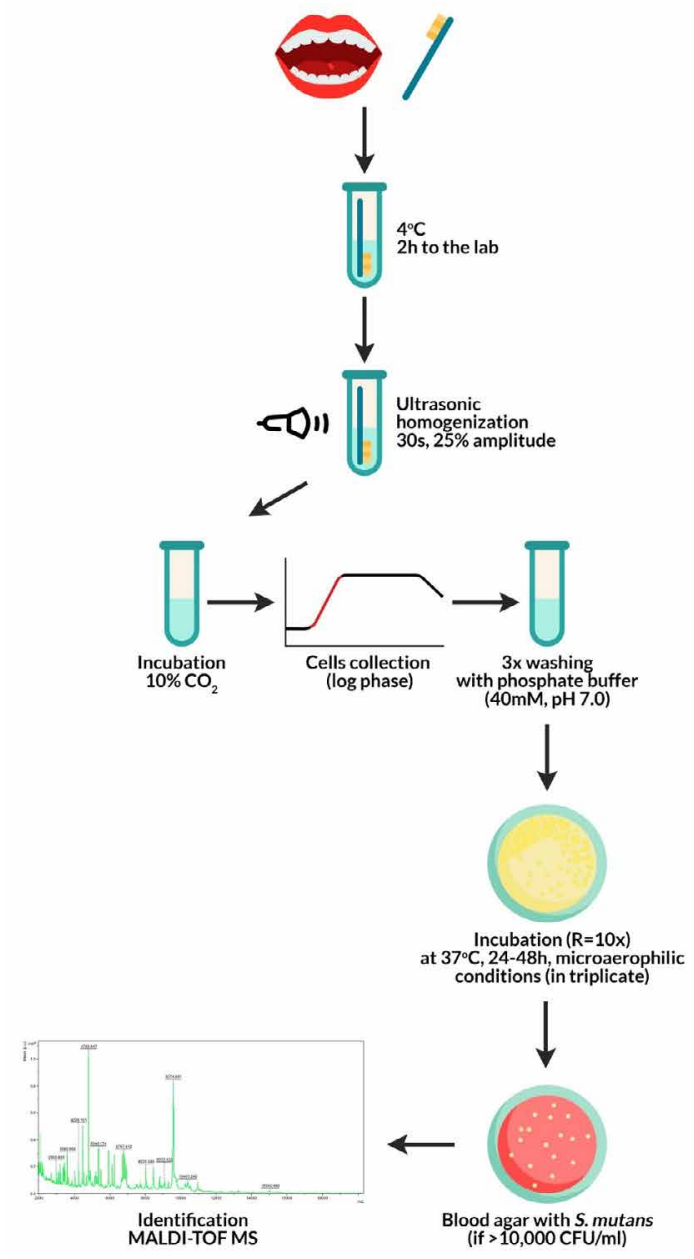

Figure 2. Test protocol: from plaque collection from children to obtaining pure S. mutans isolates

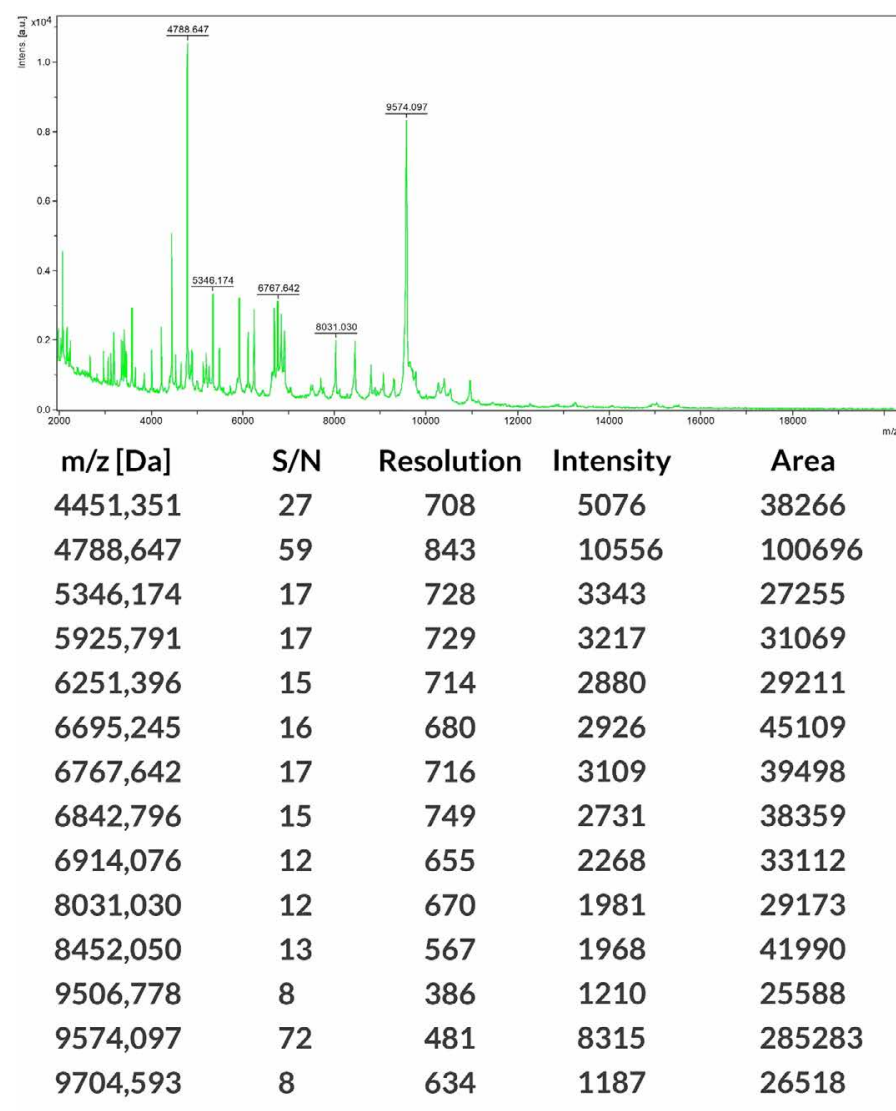

Figure 3. Sample result of an identification of $S$. mutans bacteria strains isolated from dental plaque using laser assisted desorption/ionization - time-of-flight (MALDI-TOF) performed with a mass spectrometer (Bruker Daltonik, Germany) with MALDI Biotyper software (v 3.1) (MALDI) (Biotyper Library v 3.4; Bruker Daltonik)

bacterial cultures in $5 \mathrm{~mL}$ PBS to achieve a bacterial cell concentration of $10^{6} \mathrm{CFU} / \mathrm{mL}$. The density of the resulting inoculum was measured using a MicroSpeak densitometer and confirmed by single colony counting after 24-hour growth on BHI blood medium under the abovespecified conditions.

\section{Biofilm propagation}

Biofilm propagation was determined based on the commonly accepted microtiter plate model, in which the biofilm grows on the bottom and walls of the wells, or on slides located at the bottom of the wells of the microtiter plate [17]. Streptococcus mutans clinical strains were selected as the recognized etiologic agent of ECC. Biofilm propagation was carried out on polystyrene slides placed vertically on the bottom of 24-well microtiter plates in accordance with the protocol from our previous study [18]. The rate of bacterial growth in the biofilm was assessed in the presence of $0.01 \%$ xylitol $(0.66 \mathrm{mM}$ in medium). The crystal violet $(\mathrm{CV})$ staining was used to determine the biomass of the produced/degraded biofilm [19].

\section{Monospecies biofilm}

A standardized suspension of $S$. mutans bacteria (with a density of $1 \times 10^{6} \mathrm{CFU} \mathrm{S.} \mathrm{mutans} / \mathrm{mL}$ ) in a volume of $100 \mu \mathrm{L}$ was transferred to the wells of a microtiter plate in BHI broth enriched with $0.01 \%$ xylitol. Incubation of inoculated bacterial cultures was carried out under microaerophilic conditions $\left(85 \% \mathrm{~N}_{2}, 10 \% \mathrm{CO}_{2}, 5 \% \mathrm{O}_{2}\right)$ for 90 minutes at $37^{\circ} \mathrm{C}$ to initiate the attachment of microorganisms. Subsequently, 
the wells were washed twice using PBS solution. In the next stage, 100 $\mu \mathrm{L}$ fetal bovine serum (FBS) was added to initiate biofilm propagation. Then, the microplates were incubated for 2 hours under the conditions described above. Subsequently, the plates were rinsed twice using PBS and $100 \mu \mathrm{L}$ of $\mathrm{BHI}$ broth enriched with $0.01 \%$ xylitol was added. The negative control was $100 \mu \mathrm{L}$ of $\mathrm{BHI}+0.01 \%$ xylitol without bacteria (medium control). Continuous biofilm growth was ensured by the addition of $200 \mu \mathrm{L}$ of BHI broth with $0.01 \%$ xylitol to $S$. mutans wells. Subsequently, the bacterial plates were incubated under microaerophilic conditions at $37^{\circ} \mathrm{C}$ for $8,24,48$ and $72 \mathrm{~h}$ (Figure 4 ).

\section{Calculation of bacteria count in a biofilm $(\mathrm{CFU} / \mathrm{mL})$}

After washing three times with sterile R-PBS at fixed time points (after 8, 24, 48, 72 hours of incubation), the biofilms obtained on the bottom and walls of the microtiter plate were removed using an ultrasonic homogenizer (Hielscher UP50H, Teltow, Germany for 20 sec. $25 \%$ amplitude). Serial dilutions were prepared from the resulting suspensions, and inoculated with mitis salivarius-bacitracin agar with MSBS sucrose in a volume of $100 \mu \mathrm{L}$ of $S$. mutans. The plates were grown for another 48 hours in the microaerophilic conditions. The number of grown bacterial colonies $(\mathrm{CFU} / \mathrm{mL})$ was calculated. The experiment was performed in three repetitions.

\section{Biofilm biomass-determination}

CV staining was used (after 8, 24, 48 and 72-hour growth) in order to determine the biomass of the structure produced. The fixing of the resulting bacterial film structure was carried out in $99 \%$ methanol (Sigma-Aldrich, Poznań, Poland) over a period of $20 \mathrm{~min}$. The supernatants were removed and the microtiter plates were dried in the air. The resulting dried biofilm structure was stained with 100

Mono-species S. mutans biofilm

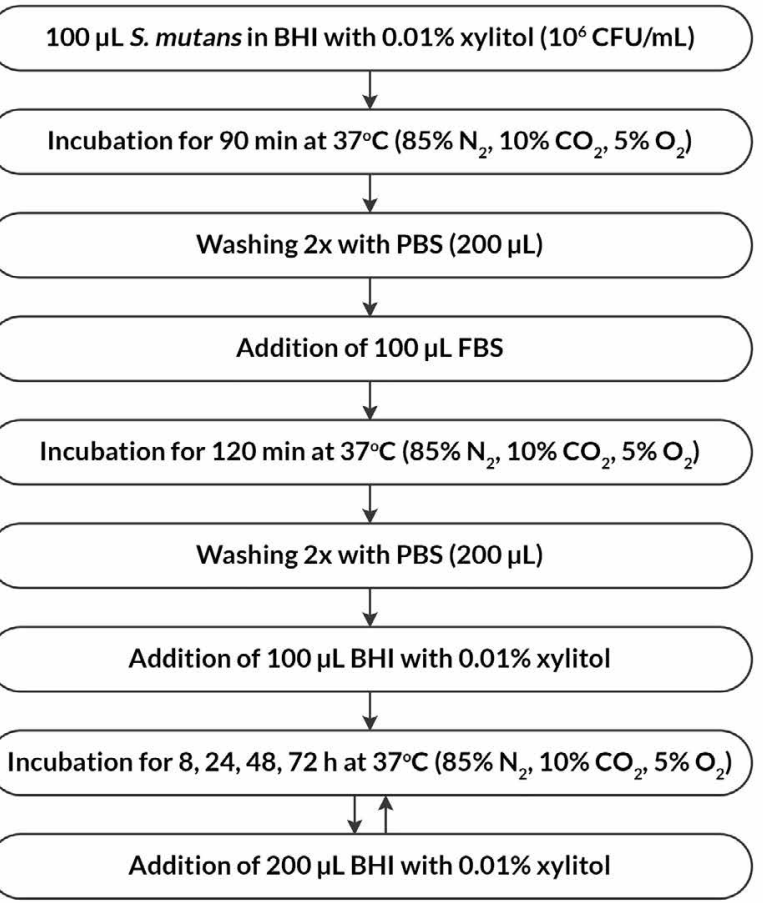

Figure 4. Flowchart of the study design $\mu \mathrm{L}$ of $0.1 \%$ crystal violet $(\mathrm{CV})$ over 10 minutes. After this time, the $\mathrm{CV}$ was removed through washing the plate wells with sterile PBS three times. The stain bound in the biofilm structure was released using $95 \%$ ethanol (Sigma-Aldrich, Poznań, Poland) in a volume of $200 \mu \mathrm{L} .125$ $\mu \mathrm{L}$ of microtiter plate wells were transferred into the wells of blank plates. The mass of the produced biofilm was determined based on the measured absorbance at $540 \mathrm{~nm}$. The experiment was carried out in duplicate at two independent time points at room temperature. The biofilm curves of $S$. mutans were plotted.

\section{Evaluation of the biofilm formed in a scanning electron microscopy (SEM)}

Round $13 \mathrm{~mm}$ diameter primary slides (Scientific Agar, Stansted, UK), which were placed in wells of a 24 -well plate, in accordance with our previous findings, were used for the biofilm evaluation after 8,24 , 48 and 72 hours [16].

Based on previously scheduled biofilm development timelines, the slides were conditioned in $1 \mathrm{~mL}$ of $2.5 \%$ glutaraldehyde for $1 \mathrm{~h}$ and dehydrated in serial dilutions $(50,70,80,90,95,100 \%$ by volume) of ethanol: 20 minutes for each dilution. Finally, the slides were dried in $100 \%$ ethanol for $1 \mathrm{~h}$ and subsequently stored in a $\mathrm{CO}_{2}$ incubator until the following day. Such dried preparations were placed on copper disks and sprayed with gold from a golden wire $\mathrm{AU} 4 \mathrm{~N}$ with a diameter of $0.2 \mu \mathrm{m}(160 \mathrm{~s}, 40 \mathrm{~mA})$. Analysis of the samples was carried out with a scanning electron microscope (JEOL JSM-35CF, SEM, Jeol, Japan) at $20-25 \mathrm{kV}$ in the Laboratory of Scanning Electron Microscopy, Laboratory of the Otolaryngology Clinic of the University Hospital in Kraków.

\section{Statistical methods used}

Statistical analysis was performed in the $\mathrm{R}$ environment, version 3.5.1 (R Development Core Team, 2009). The normality of the variable distribution was examined using the Shapiro-Wilk test. The significance level of 0.05 was adopted in the analysis. Thus, all $p$ values below 0.05 were interpreted as indicating significant relationships. The comparison of values of qualitative variables in the groups was conducted using the chi-square test. The comparison of the values of quantitative variables in two groups was performed using the Student's t-test (when the variable had a normal distribution in these groups) or the MannWhitney test (otherwise). Correlations between quantitative variables (comparison of CFU (log-transformed) and biofilm biomass by optical density measurement, OD) were analyzed using Pearson's (when both had a normal distribution) or Spearman's correlation coefficients (otherwise). The relationship strength was interpreted according to the following scheme proposed by Hinkle, et al. [20]: $|\mathrm{r}| \geq 0.9$-very strong relationship, $0.7 \leq|\mathrm{r}|<0.9$ - strong relationship, $0.5 \leq|\mathrm{r}|<0.7-$ medium-strong relationship, $0.3 \leq|\mathrm{r}|<0.5$-weak relationship, $|\mathrm{r}|<$ 0.3 -very weak (negligible) relationship.

\section{Results}

\section{Study design}

Clinical S. mutans isolates derived from dental plaque of children ( $n=64$, mean age: $4.7 \pm 0.81$ years) affected by carious disease (with early carious lesions of enamel and those with cavities) and from healthy children.

The patients were divided into two groups, i.e., the study group, children with advanced caries (codes 3-6 according to the ICDAS classification, $\mathrm{n}=33$ ) and the control group consisting of children 
with teeth not affected by carious lesions and children with enamel discolorations (codes 0,1 and 2 according to the ICDAS classification, $\mathrm{n}=31)$.

There were 27 girls and 37 boys across the studied groups. 33 children (12 girls and 21 boys) were included in the study group, and a total of 31 children (15 girls and 16 boys) constituted a control group. There were no significant age-dependent differences in the studied groups, as illustrated in Table 1.

\section{Description of isolated $S$. mutans species}

S. mutans isolates formed the biofilm shown in Figure 5-1,5-2.-AD. The result of the identification is presented on an exemplary figure using a mass spectrometer (Bruker Daltonik, Germany) with MALDI

Table 1. Characteristics of the studied groups

\begin{tabular}{|c|c|c|c|c|c|}
\hline \multicolumn{2}{|c|}{ Feature } & $\begin{array}{c}\text { Cavity } \\
(\mathbf{N}=33)\end{array}$ & $\begin{array}{c}\text { No cavity } \\
(\mathbf{N}=31)\end{array}$ & $\begin{array}{c}\text { In total } \\
(\mathbf{N}=64)\end{array}$ & p * \\
\hline \multirow{3}{*}{ age } & mean \pm SD & $4.7 \pm 0.73$ & $4.71 \pm 0.9$ & $4.7 \pm 0.81$ & 0.868 \\
\cline { 2 - 7 } & median & 5 & 5 & 5 & NP \\
\cline { 2 - 7 } & quartiles & $4-5$ & $4-5$ & $4-5$ & \\
\hline \multirow{2}{*}{ sex } & Girls & $12(36.36 \%)$ & $15(48.39 \%)$ & $27(42.19 \%)$ & 0.471 \\
\cline { 2 - 7 } & Boys & $21(63.64 \%)$ & $16(51.61 \%)$ & $37(57.81 \%)$ & chi2 \\
\hline
\end{tabular}

* chi $2=$ chi-square test, $\mathrm{NP}=$ no normality of distribution, non-parametric analysis, Kruskal-Wallis test
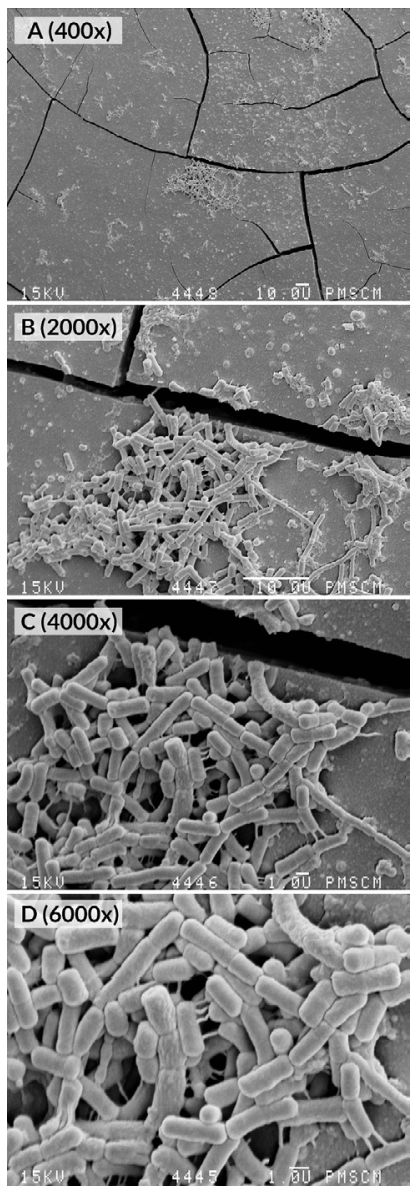

Figure 5-1. Images from the SEM. (A-D) Monospecies biofilm after 24 (A-D) and 48 hours (E-F) biofilm propagation. Structure of a monospecies biofilm cultured under microaerophilic conditions $\left(\mathrm{pCO}_{2} 10 \%, 37^{\circ} \mathrm{C}, \mathrm{pH} 7.0\right)$ in $\mathrm{FBS}$ containing all necessary growth factors; in and without the presence of a xylitol substrate $(0.01 \%)(\mathrm{G}-\mathrm{H})$. Original magnification: $400 \times, 2000 \times, 4000 \times, 6000 \times$

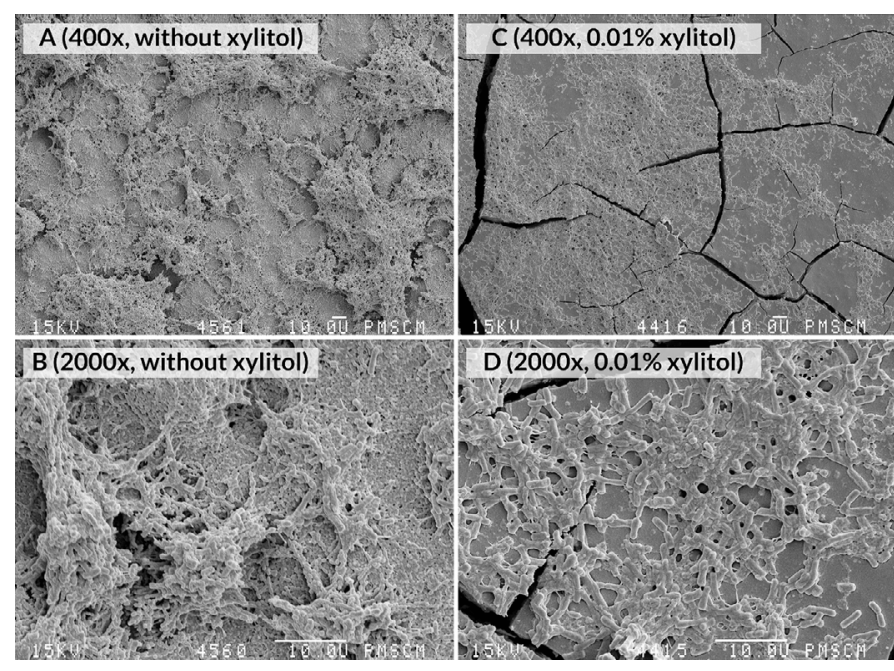

Figure 5-2. Images from the SEM. (A-D) S. mutans monospecies biofilm after 48 hours of culture. Structure of a monospecies biofilm cultured under microaerophilic conditions $\left(\mathrm{pCO}_{2} 10 \%, 37^{\circ} \mathrm{C}, \mathrm{pH} 7.0\right)$ in FBS containing all necessary growth factors; in and without the presence of a xylitol substrate $(0.01 \%)(\mathrm{G}-\mathrm{H})$. Original magnification: $400 \times, 2000 \times$

Biotyper software (v 3.1) (MALDI Biotyper Library v 3.4, Bruker Daltonik) (Figure 3).

\section{Evaluation of the biofilm formation effect after S. mutans treatment with $0.01 \%$ xylitol}

Differences in the numbers CFU/mL of $S$. mutans after 8,24 , and $48 \mathrm{~h}$ were statistically significant, as illustrated in Table 2 and Figures 6-7. Under the influence of xylitol, $S$. mutans strains derived from children with dental cavity caries formed a larger biofilm $(\mathrm{CFU} / \mathrm{mL})$ after $24 \mathrm{~h}$ of culturing, whereas a statistically significant decrease in the biofilm formation in these strains was observed after $48 \mathrm{~h}$ compared to the strains without xylitol (Table 2, Figure 6). This trend also persisted after 72 hours of biofilm formation, although these differences were not statistically significant.

Under the influence of xylitol, S. mutans strains isolated from children without carious cavities formed a larger biofilm $(\mathrm{CFU} / \mathrm{mL})$ after 8 and $24 \mathrm{~h}$ of culturing, while a statistically significant reduction in biofilm formation was observed among these strains after $48 \mathrm{~h}$ compared to the strains without xylitol (Table 2, Figure 7).

The differences in the total biofilm biomass of $S$. mutans after 8, 24, 48 and $72 \mathrm{~h}$ were statistically significant (Table 3 ), in both the study and control groups. The biomass (OD) of xylitol-affected biofilm was lower than that without xylitol at all time points, among both the isolates of children with cavity caries (Figure 8 ) and the isolates of children without carious cavities (Table 3, Figure 9).

The inhibitory effect of xylitol on monospecies biofilm formation by $S$. mutans is shown in Figures 6-8 and 5.G-H SEM images after a 24-hour culturing. Photographs show quantitatively and structurally different bacterial cells in a monospecies biofilm, both treated and untreated with xylitol.

\section{Discussion}

The study showed that the effectiveness of xylitol itself varies, depending on the time of exposure and concentration. A prerequisite for the formation of tooth demineralization is the presence of cariogenic strains in the dental plaque, and not only cariogenic planktonic strains [21]. Inhibition of plaque formation and an evaluation of cariogenic $S$. 
Kościelniak D (2019) Low concentration of xylitol improves children tooth protection against Streptococcus mutans biofilm formation

Table 2. Xylitol effect on the ability to form biofilms by determining the amount of $S$. mutans bacterial colonies in the biofilm (CFU/mL)

\begin{tabular}{|c|c|c|c|c|}
\hline \multicolumn{5}{|c|}{ Studied group } \\
\hline \multicolumn{2}{|c|}{$\log (C F U / m L)$} & Cavity $(\mathrm{N}=33)$ & Cavity + Xylitol $(\mathrm{N}=33)$ & $p^{*}$ \\
\hline \multirow{3}{*}{$8 \mathrm{~h}$} & Mean \pm SD & $6.26 \pm 0.04$ & $6.27 \pm 0.05$ & 0.315 \\
\hline & median & 6.26 & 6.26 & NP \\
\hline & quartiles & $6.23-6.28$ & $6.26-6.3$ & \\
\hline \multirow{3}{*}{$24 \mathrm{~h}$} & mean $\pm \mathrm{SD}$ & $6.43 \pm 0.04$ & $6.45 \pm 0.04$ & 0.001 \\
\hline & median & 6.43 & 6.45 & NP \\
\hline & quartiles & $6.41-6.45$ & $6.41-6.48$ & \\
\hline \multirow{3}{*}{$48 \mathrm{~h}$} & mean $\pm \mathrm{SD}$ & $7.54 \pm 0.06$ & $7.52 \pm 0.07$ & 0.001 \\
\hline & median & 7.56 & 7.53 & NP \\
\hline & quartiles & $7.53-7.58$ & $7.51-7.57$ & \\
\hline \multirow{3}{*}{$72 \mathrm{~h}$} & mean $\pm \mathrm{SD}$ & $8.64 \pm 0.04$ & $8.63 \pm 0.05$ & 0.617 \\
\hline & median & 8.64 & 8.63 & NP \\
\hline & quartiles & $8.61-8.66$ & $8.6-8.67$ & \\
\hline \multicolumn{5}{|c|}{ Control group } \\
\hline \multicolumn{2}{|c|}{$\log (\mathrm{CFU} / \mathrm{ml})$} & No cavity $(\mathbf{N}=31)$ & No cavity + Xylitol $(\mathrm{N}=31)$ & $\mathbf{p}^{*}$ \\
\hline \multirow{3}{*}{$8 \mathrm{~h}$} & mean $\pm \mathrm{SD}$ & $5.14 \pm 0.05$ & $5.18 \pm 0.05$ & $<0.001$ \\
\hline & median & 5.15 & 5.2 & NP \\
\hline & quartiles & $5.13-5.18$ & $5.15-5.22$ & \\
\hline \multirow{3}{*}{$24 \mathrm{~h}$} & mean $\pm \mathrm{SD}$ & $5.29 \pm 0.05$ & $5.3 \pm 0.05$ & $<0.001$ \\
\hline & median & 5.28 & 5.28 & NP \\
\hline & quartiles & $5.26-5.31$ & $5.28-5.32$ & \\
\hline \multirow{3}{*}{$48 \mathrm{~h}$} & mean $\pm \mathrm{SD}$ & $6.4 \pm 0.04$ & $6.39 \pm 0.06$ & $<0.001$ \\
\hline & median & 6.4 & 6.4 & NP \\
\hline & quartiles & $6.38-6.43$ & $6.36-6.43$ & \\
\hline \multirow{3}{*}{$72 \mathrm{~h}$} & mean $\pm \mathrm{SD}$ & $7.54 \pm 0.02$ & $7.54 \pm 0.03$ & $<0.001$ \\
\hline & median & 7.53 & 7.54 & NP \\
\hline & quartiles & $7.52-7.56$ & $7.51-7.57$ & \\
\hline
\end{tabular}

$* P=$ Normal distribution in the groups, 'Student's t-test NP = No normality of distribution in groups, Mann-Whitney test
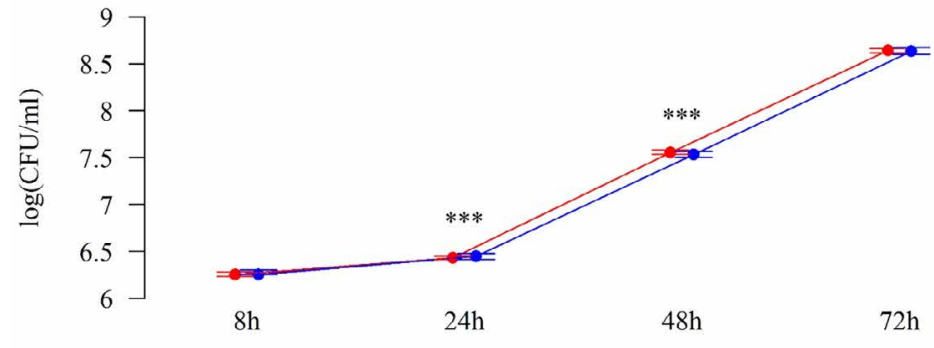

- No Xylitol - Xylitol

- Median I Quartiles

Figure 6. Effect of $0.01 \%$ xylitol on the ability of $S$. mutans isolated from children with caries to form biofilm
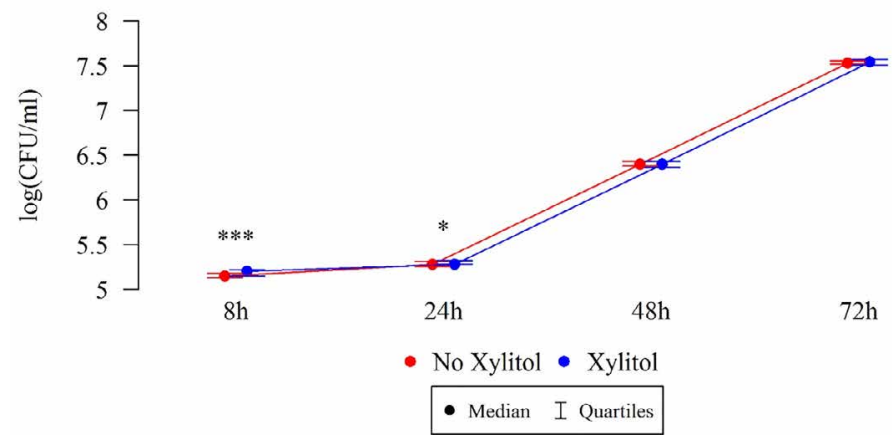

Figure 7. Effect of $0.01 \%$ xylitol on the ability of S. mutans isolated from children without caries to form biofilm 
Kościelniak D (2019) Low concentration of xylitol improves children tooth protection against Streptococcus mutans biofilm formation

Table 3. Effect of $0.01 \%$ xylitol on the ability of biofilm formation by determining the biomass of S. mutans biofilm (OD)

\begin{tabular}{|c|c|c|c|c|}
\hline \multicolumn{5}{|c|}{ Studied group } \\
\hline OD & & Cavity $(\mathrm{N}=33)$ & Cavity + Xylitol (N=33) & $\mathbf{p}^{*}$ \\
\hline \multirow[t]{3}{*}{$8 \mathrm{~h}$} & mean $\pm \mathrm{SD}$ & $0.08 \pm 0.006$ & $0.078 \pm 0.006$ & $<0.001$ \\
\hline & median & 0.079 & 0.077 & NP \\
\hline & quartiles & $0.076-0.084$ & $0.074-0.083$ & \\
\hline \multirow[t]{3}{*}{$24 \mathrm{~h}$} & mean $\pm \mathrm{SD}$ & $0.133 \pm 0.008$ & $0.131 \pm 0.009$ & $<0.001$ \\
\hline & median & 0.135 & 0.133 & NP \\
\hline & quartiles & $0.129-0.137$ & $0.124-0.136$ & \\
\hline \multirow[t]{3}{*}{$48 \mathrm{~h}$} & mean $\pm \mathrm{SD}$ & $0.188 \pm 0.005$ & $0.186 \pm 0.006$ & $<0.001$ \\
\hline & median & 0.187 & 0.184 & NP \\
\hline & quartiles & $0.185-0.194$ & $0.182-0.192$ & \\
\hline \multirow[t]{3}{*}{$72 \mathrm{~h}$} & mean $\pm \mathrm{SD}$ & $0.252 \pm 0.015$ & $0.251 \pm 0.008$ & $<0.001$ \\
\hline & median & 0.254 & 0.249 & NP \\
\hline & quartiles & $0.248-0.258$ & $0.245-0.255$ & \\
\hline \multicolumn{5}{|c|}{ Control group } \\
\hline OD & & No cavity $(\mathrm{N}=31)$ & No cavity + Xylitol $(\mathrm{N}=\mathbf{3 1})$ & $\mathbf{p}^{*}$ \\
\hline \multirow[t]{3}{*}{$8 \mathrm{~h}$} & mean $\pm \mathrm{SD}$ & $0.05 \pm 0.007$ & $0.049 \pm 0.007$ & $<0.001$ \\
\hline & median & 0.048 & 0.047 & NP \\
\hline & quartiles & $0.046-0.052$ & $0.045-0.05$ & \\
\hline \multirow[t]{3}{*}{$24 \mathrm{~h}$} & mean $\pm \mathrm{SD}$ & $0.093 \pm 0.005$ & $0.092 \pm 0.005$ & $<0.001$ \\
\hline & median & 0.093 & 0.092 & $\mathrm{P}$ \\
\hline & quartiles & $0.091-0.095$ & $0.09-0.094$ & \\
\hline \multirow[t]{3}{*}{$48 \mathrm{~h}$} & mean $\pm \mathrm{SD}$ & $0.142 \pm 0.009$ & $0.14 \pm 0.009$ & $<0.001$ \\
\hline & median & 0.138 & 0.136 & NP \\
\hline & quartiles & $0.136-0.147$ & $0.134-0.144$ & \\
\hline \multirow[t]{3}{*}{$72 \mathrm{~h}$} & mean $\pm \mathrm{SD}$ & $0.195 \pm 0.014$ & $0.19 \pm 0.01$ & $<0.001$ \\
\hline & median & 0.195 & 0.19 & NP \\
\hline & quartiles & $0.186-0.2$ & $0.184-0.198$ & \\
\hline
\end{tabular}

$* P=$ Normal distribution in the groups, Student's $t$-test $N P=$ No normality of distribution in groups, Mann Whitney test

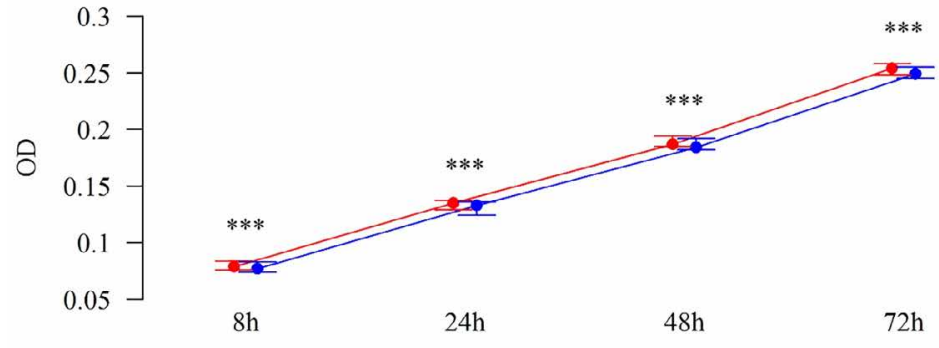

- No Xylitol - Xylitol

- Median I Quartiles

Figure 8. Effect of $0.01 \%$ xylitol on the ability of $S$. mutans isolated from children with caries to form biofilm (OD)

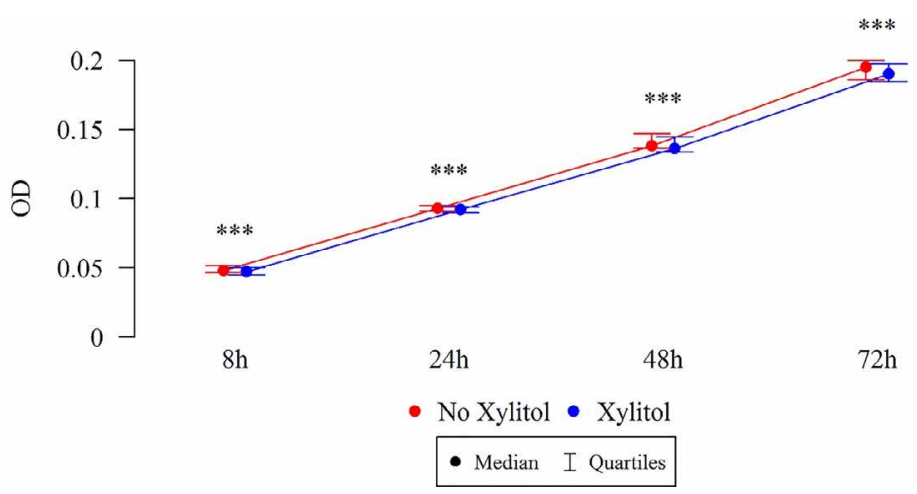

Figure 9. Effect of $0.01 \%$ xylitol on the ability of $S$. mutans isolated from healthy children to form biofilm 
mutans quantities in order to analyze the anti-biofilm activity of xylitol itself is a prerequisite of its application as an alternative means of anticaries protection in everyday practice. The collected data showed that the commonly available Finnish xylitol sold as a sweetener shows good anti-biofilm activity even at the very low concentration of $0.01 \%$. It was determined in in vitro studies on the effect of low xylitol concentrations on streptococcal growth that a $0.01 \%$ xylitol concentration may have an inhibitory effect, with the indication that $0.1 \%$ and $1 \%$ concentrations gave more distinct effects [22,23]. In clinical studies in which xylitol was administered to patients mainly as chewing gums or coated tablets, it demonstrated the ability to reduce the count of $S$. mutans isolated from patients and to reduce dental plaque mass [24-27]. The results of our study confirm the legitimacy of the use of xylitol products, which may be particularly attractive among the youngest age groups due to the method of administration and its sweet taste. In fact, if inhibition of plaque formation depends on bacterial strains (their lower or higher sensitivity), the reduction of pre-formed biofilms was significantly supported for all strains tested, compared to xylitol non-treated strains where the amount of plaque was incomparably higher. The presented results confirm previous findings regarding the legitimacy of xylitol use and the possibility of its application on a larger scale in industry as a means of protection against caries in foodstuffs. However, there's a need for more studies to determine the acceptable minimum effective inhibitory concentrations of xylitol in children.

There are an increasing number of studies in available databases attempting to determine the potential xylitol anti-biofilm mechanism, which means that this topic has not yet been sufficiently explored. In the largest number of published studies, authors explain the inhibitory effect of xylitol by its ability to reduce the production of an extracellular matrix (EPS) by pathogenic S. mutans [28]. However, to our knowledge, our study is one of the few studies that assess the anti-biofilm effects of xylitol commonly available on sale in an ex vivo model, on clinical strains isolated from the source of infection. Work on wild strains, not isolates commercially available as in the case of xylitol, is important, since it allows for the actual evaluation of its effect, also taking into account the possibility of the occurrence of the xylitol resistance effect described in the literature and observed in the case of xylitol consumers. It has been described that the biofilm formed by xylitolsensitive strains (XS) in the presence of xylitol achieves lower thickness and lower bacterial density than those formed by xylitol-resistant (XR) strains. Additionally, there is a difference in the coaggregation of both strains to streptococci which are early colonizers in the oral cavity in the presence of sucrose. This results from the fact that XR S. mutans do not form a durable biofilm and it is easier to leach out these bacteria, which explains why number of XR strains in this structure is smaller than the number of XS S. mutans, and why it appears more often in the saliva of habitual consumers of xylitol [21,28]. The results of our study are consistent with results of other studies carried out by research teams and confirm the anti-biofilm effects of xylitol. It should also be underlined that the anti-biofilm effect has also been described for other polyols or pentoses, such as erythritol or ribose, which have been the subject of many other studies [21,22,29,30].

In the literature on the subject, there are a number of studies assessing the effectiveness of xylitol supplementation in the prevention of carious disease in children. The results vary: from a lack of effect to a significant reduction of caries.

Milgrom et al. investigated the effectiveness of a syrup containing xylitol or a mixture of xylitol and sorbitol in children aged $15.0 \pm$ 2.7 months for $10.5 \pm 2.2$ months [31]. He showed that twice daily administration of a total $8 \mathrm{~g}$ xylitol dose during the eruption of milk teeth resulted in a $70 \%$ reduction of caries in relation to the control group. Similarly, Zhan et al. found that 6-35-month-old children cleaning teeth and gums for a year, 3 times a day using a special xylitol wipes (daily dose-4.2 g xylitol) in addition to the usual toothbrush used twice a day, showed a significant drop in the development of new carious lesions compared to the control group [32]. Mäkinen et al. evaluated the efficacy of topical xylitol administration in the form of cotton swabs, soaked with a $45 \%$ xylitol solution once or twice a day in children aged 6 to 36 months [33]. The daily dose of xylitol applied to tooth surfaces was about $13.5 \mathrm{~g}$. A significant reduction in caries was found in children aged 7 years, compared to the control group: about 2 times lower risk of caries (2.1 and 4.0, respectively). In turn, Hanno et al. simultaneously administered xylitol to mothers (as chewing gum) and children (in the form of tablets) 3 times a day for 3 months and did not find any differences in the level of caries in comparison to the control group [34].

In a study of the cariostatic efficacy of xylitol delivered to children aged 4-5 years in toothpaste, Chi et al., also did not find any significant differences in the prevalence of caries among children brushing teeth with $1400 \mathrm{ppm}$ fluoride and 31\% xylitol, and children using toothpaste with $1450 \mathrm{ppm}$ fluoride and sorbitol [35]. Analysis of five randomized controlled trials conducted by Marghalani et al. showed a slight effect of xylitol on the reduction of caries in children [36]. Studies with higher doses of xylitol (more than $4 \mathrm{~g}$ per day) showed a moderate reduction in caries, and all of these studies were characterized by significant heterogeneity and very low evidence quality [35].

A number of these studies justify the use of xylitol as part of a program of primary caries prophylaxis leading to a reduction in the level of carious bacteria already present in the oral cavity without caries symptoms. However, more studies are needed to assess the effect of xylitol at various concentrations of fluoride in commercially available oral care products to determine its borderline concentrations that inhibit the development of dental plaque.

In contrast to our earlier observations with sucrose as a procariogenic sugar, xylitol is not fermented, so it cannot be used by $S$. mutans for energy production, but it can also be used as a nutrient substrate for other reactions that determine bacterial survival in a biofilm. Inhibition of the subsequent formation of biofilm by $S$. mutans is affected by the low concentrations of xylitol used, as is observed in this study $[18,35,37,38]$.

By comparing our results with the results of other researchers, it can be noticed that xylitol, also when used at low concentrations, supports biofilm formation ability in some studies. This phenomenon may in turn be caused by the presence of other, alternative sweeteners in the composition of xylitol, which cause dental plaque growth $[39,40]$. It is suggested that some of the ingredients added to food products, such as corn or cellulose powder-Chinese xylitol ingredients, may be responsible for this effect.

The use of xylitol by Streptococcus requires further research, especially in mixed biofilm models that reflect the conditions prevailing in the oral cavity. Adaptation abilities of the cariogenic microorganisms seem less likely for this polyol compared to traditional food sugar and gives hope for expanding the list of potential anti-caries agents, especially for the youngest age groups.

The project of clinical strain examination presented in this study has a number of limitations, such as the lack of salivary effects for the 
whole variety of oral microorganisms that interact with $S$. mutans and that may have both erosive and protective effects on the tooth enamel surface. In addition, for better assessment of the xylitol effect on tooth enamel surfaces, we plan further studies in which we will determine the interactions between plaque bacterial flora, xylitol and various filling materials widely used in dentistry.

\section{Conclusions}

Xylitol available for sale as a substitute for traditional sugar has confirmed good anti-biofilm properties at low concentrations, which demonstrated its significant potential as a means of limiting the influence of demineralization-promoting factors (bacterial factors of carious disease) and supporting the remineralization process. This study confirms the validity of xylitol application as an alternative means of caries prophylaxis.

\section{Authors' contributions}

W.K., D.K. article design, test design, execution of all tests, statistical analysis, manuscript writing. A.J., D.K., M.S., I.G.-M., I.K., M. J.-K. patient qualification for the study, clinical material collection, manuscript writing. P.V. execution of a part of the tests. M.P. performance of flow cytometry analysis. M.M., K.K. review of selected literature and manuscript writing. W.K. editorial amendments. All authors have read and approved the final article.

\section{Acknowledgements}

The authors would like to thank Professor Ryszard Drożdż, Head of the Department of Medical Diagnostics, Jagiellonian University Medical College, Krakow, Poland for providing the biochemical laboratory to perform the biochemical part of the study. We would like to thank Professor Elżbieta Karczewska, Head of the Department of Pharmaceutical Microbiology, Jagiellonian University Medical College, Krakow, Poland for providing the microbiological laboratory to perform the microbiological part of the study. The authors would like to thank Professor Jacek Składzień, Head of the Department of Otorhinolaryngology, Jagiellonian University Medical College, Krakow and Mrs. Katarzyna Zagórska-Świeży of Department of Otorhinolaryngology, Jagiellonian University Medical College, Krakow, Poland for providing the scanning electron microscope to perform the scanning electron microscoping part of the study.

\section{Funding}

This study was supported by the Jagiellonian University [Program Nos K/ZDS/007071, K/ZDS/007911, K/ZDS/007912, K/ZDS/007910].

\section{Conflicts of interest}

The authors declare no conflict of interest.

\section{References}

1. Forssten SD, Björklund M, Ouwehand AC (2010) Streptococcus mutans, caries and simulation models. Nutrients 2: 290-298. [Crossref]

2. Trahan L (1995) Xylitol: a review of its action on mutans streptococci and dental plaque--its clinical significance. Int Dent J 45: 77-92. [Crossref]

3. Jenson L, Budenz AW, Featherstone JDB, Ramos-Gomez FJ, Spolsky VW, et al. (2007) Clinical protocols for caries management by risk assessment. J Calif Dent Assoc 35: 714-723.

4. Damle SG, Yadav R, Garg S, Dhindsa A, Beniwal V, et al. (2016) Transmission of mutans streptococci in mother-child pairs. Indian J Med Res 144: 264-270. [Crossref]
5. Horst JA (2018) Silver Fluoride as a Treatment for Dental Caries. Adv Dent Res 29: 135-140. [Crossref]

6. Featherstone JD1 (1999) Prevention and reversal of dental caries: role of low-level fluoride. Community Dent Oral Epidemiol 27: 31-40. [Crossref]

7. McDonagh MS, Whiting PF, Wilson PM, Sutton AJ, Chestnutt I, et al. (2000) Systematic review of water fluoridation. BMJ 321: 855-859. [Crossref]

8. Tschoppe P, Zandim DL, Martus P, Kielbassa AM (2011) Enamel and dentine remineralization by nano-hydroxyapatite toothpastes. J Dent 39: 430-437. [Crossref]

9. Nascimento MM (2018) Potential Uses of Arginine in Dentistry. Adv Dent Res 29: 98-103. [Crossref]

10. Adams SE, Arnold D, Murphy B, Carroll P, Green AK, et al. (2017) A randomised clinical study to determine the effect of a toothpaste containing enzymes and proteins on plaque oral microbiome ecology. Sci Rep 7: 43344. [Crossref]

11. Nayak PA, Nayak UA, Khandelwal V (2014) The effect of xylitol on dental caries and oral flora. Clin Cosmet Investig Dent 6: 89-94. [Crossref]

12. WHO (1997) Oral health surveys: basic methods. (4th Edn) World Health Organization, Geneva p. 6.

13. WHO (2013) Oral health surveys: basic methods. (5th Edn) World Health Organization, Geneva p. 125.

14. (ICDAS II) (2012) Rationale and Evidence for the International Caries Detection and Assessment System Baltimore. International Caries Detection and Assessment System Coordinating Committee, MD, USA.

15. Wei SH, Lang KP (1981) Periodontal epidemiological indices for children and adolescents: I. Gingival and periodontal health assessments. Pediatr Dent 3: 353-360. [Crossref]

16. Krzysciak W, Koscielniak D, Papiez M, Jurczak A, Vyhouskaya P (2017) Methods of Biotyping of Streptococcus mutans Species with the Routine Test as a Prognostic Value in Early Childhood Caries. Evid Based Complement Alternat Med 2017: 6859543. [Crossref]

17. Lebeaux D, Chauhan A, Rendueles O, Beloin C (2013) From in vitro to in vivo Models of Bacterial Biofilm-Related Infections. Pathogens 2: 288-356. [Crossref]

18. Krzysciak W, Papiez M, Jurczak A, Koscielniak D, Vyhouskaya P, et al. (2017) Relationship between Pyruvate Kinase Activity and Cariogenic Biofilm Formation in Streptococcus mutans Biotypes in Caries Patients. Front Microbiol 8: 856. [Crossref]

19. Peeters E, Nelis HJ, Coenye T (2008) Comparison of multiple methods for quantification of microbial biofilms grown in microtiter plates. $J$ Microbiol Methods 72: 157-165. [Crossref]

20. Hinkle DE, Wiersma W, Jurs SG (2003) Applied statistics for the behavioral sciences. (5th Edn) Houghton Mifflin, Boston: p. 756.

21. Lee S-H, Choi B-K, Kim Y-J (2012) The cariogenic characters of xylitol-resistant and xylitol-sensitive Streptococcus mutans in biofilm formation with salivary bacteria. Arch Oral Biol 57: 697-703. [Crossref]

22. Gholam Reza Ghezelbash (2012) Comparative inhibitory effect of xylitol and erythritol on the growth and biofilm formation of oral Streptococci. African Journal of Microbiology Research p. 6.

23. Söderling EM (2009) Xylitol, mutans streptococci, and dental plaque. Adv Dent Res 21: 74-78. [Crossref]

24. Runnel R, Mäkinen KK, Honkala S, Olak J, Mäkinen P-L, et al. (2013) Effect of threeyear consumption of erythritol, xylitol and sorbitol candies on various plaque and salivary caries-related variables. J Dent 41: 1236-1244. [Crossref]

25. Aluckal E, Ankola AV (2018) Effectiveness of xylitol and polyol chewing gum on salivary streptococcus mutans in children: A randomized controlled trial. Indian J Dent Res 29: 445-449. [Crossref]

26. Söderling E, Isokangas P, Tenovuo J, Mustakallio S, Mäkinen KK (1991) Long-term xylitol consumption and mutans streptococci in plaque and saliva. Caries Res 25: 153157. [Crossref]

27. Lif Holgerson P, Stecksén-Blicks C, Sjöström I, Oberg M, Twetman S (2006) Xylitol concentration in saliva and dental plaque after use of various xylitol-containing products. Caries Res 40: 393-397. [Crossref]

28. Trahan L, Söderling E, Drean M-F, Chevrier M-C, Isokangas P (1992) Effect of Xylitol Consumption on the Plaque-Saliva Distribution of Mutans Streptococci and the Occurrence and Long-term Survival of Xylitol-resistant Strains. J Dent Res 71: 1785-1791. [Crossref] 
29. Lee HJ, Kim SC, Kim J, Do A, Han SY, et al. (2015) Synergistic inhibition of Streptococcal biofilm by ribose and xylitol. Arch Oral Biol 60: 304-312. [Crossref]

30. Salli KM, Forssten SD, Lahtinen SJ, Ouwehand AC (2016) Influence of sucrose and xylitol on an early Streptococcus mutans biofilm in a dental simulator. Arch Oral Biol 70: 39-46. [Crossref]

31. Milgrom P, Ly KA, Tut OK, Mancl L, Roberts MC, et al. (2009) Xylitol pediatric topical oral syrup to prevent dental caries: a double-blind randomized clinical trial of efficacy. Arch Pediatr Adolesc Med 163: 601-607. [Crossref]

32. Zhan L, Cheng J, Chang P, Ngo M, Denbesten PK, et al. (2012) Effects of xylitol wipes on cariogenic bacteria and caries in young children. J Dent Res 91: 85S-90S. [Crossref]

33. Mäkinen KK, Järvinen KL, Anttila CH, Luntamo LM, Vahlberg T (2013) Topical xylitol administration by parents for the promotion of oral health in infants: a caries prevention experiment at a Finnish Public Health Centre. Int Dent J 63: 210-224. [Crossref]

34. Hanno AG, Alamoudi NM, Almushayt AS, Masoud MI, Sabbagh HJ, et al. (2011) Effect of xylitol on dental caries and salivary Streptococcus mutans levels among a group of mother-child pairs. J Clin Pediatr Dent 36: 25-30. [Crossref]
35. Chi DL, Tut O, Milgrom P (2014) Cluster-randomized xylitol toothpaste trial for early childhood caries prevention. J Dent Child (Chic) 81: 27-32. [Crossref]

36. Marghalani AA, Guinto E, Phan M, Dhar V, Tinanoff N (2017) Effectiveness of Xylitol in Reducing Dental Caries in Children. Pediatr Dent 39: 103-110. [Crossref]

37. Kim M, Jeon J, Kim J (2018) Streptococcus mutans extracellular DNA levels depend on the number of bacteria in a biofilm. Scientific Reports 8: 13313.

38. Krzysciak W, Koscielniak D, Papiez M, Vyhouskaya P, Zagórska-Swiezy K, et al (2017) Effect of a Lactobacillus Salivarius Probiotic on a Double-Species Streptococcus Mutans and Candida Albicans Caries Biofilm. Nutrients 9: 1242. [Crossref]

39. Slane JA, Vivanco JF, Rose WE, Squire MW, Ploeg H-L (2014) The influence of low concentrations of a water soluble poragen on the material properties, antibiotic release, and biofilm inhibition of an acrylic bone cement. Mater Sci Eng C Mater Biol Appl 42 168-176. [Crossref]

40. Fathilah AR, Aishah A, Zarina MZ (2007) The Effect of Environmental Stress on the Growth of Plaque Bacteria. Research Journal of Microbiology 2: 381-386.

Copyright: (C2019 Kościelniak D. This is an open-access article distributed under the terms of the Creative Commons Attribution License, which permits unrestricted use, distribution, and reproduction in any medium, provided the original author and source are credited. 